fewer people would die if they did.

Greene found that the brains of subjects who gave the non-utilitarian response - not to push the fat man - in this case showed increased activation in regions associated with emotion, whereas the brains of the rarer utilitarian responders were activated in areas associated with working memory and reasoning. This finding has been interpreted as support for utilitarianism, the theory supposedly reflective of more rational cognitive processes. Others dispute this. In a recent study by Michael Koenig and colleagues, patients with damage in brain areas involved in the normal generation of social emotions were more likely to select a utilitarian response. One can imagine ways of spinning this result that would be less flattering to the utilitarian.

Other investigations focus on behaviour. Dropping your papers outside a phone booth in a shopping mall, you are much more likely to get help from passers-by if they have just found money in the phone's coin-return slot, according to one study. Placing a coin in the slot increased the proportion of people who stopped to help, from almost nobody to almost everybody. You are also much more likely to get change for a note from a passer-by if standing near a fragrant bakery shop than outside a "neutral-smelling dry-goods store". Many studies have confirmed that morally irrelevant features have a strong effect on whether people offer help. Some have even concluded that character is a myth: it is the situation, rather than any stable personality trait, that determines whether one does the right thing. If true, this claim poses a big challenge to aristotelian ethics, which is built on the idea that we ought to cultivate a virtuous character. However, causes can be multifactorial: the fact that situational features often have a big influence does not imply that character never has any influence. It is probably a question of degree.

Psychologists have also sought to identify the basic 'taste buds' of our moral sensibilities. Jonathan Haidt of the University of Virginia, Charlottesville, proposes we have a limited number of distinct moral modules, which get activated in response to different kinds of moral problems. Haidt's taxonomy distinguishes responses related to harm, fairness and reciprocity, hierarchy and respect, purity and pollution, in-group and out-group boundaries, and awe and elevation. If we do have all these sensibilities, one might suspect that moral theories that recognize or privilege only one or two of them are unduly restricted.

Experiments in Ethics is erudite, concise and engagingly written. Appiah assesses that experimental science is relevant to the enterprise of normative ethics, and that the relation between the two, although complex, need not be antagonistic. Returning to my analogy, Appiah recommends that our labcoated gatecrasher enter into a dialogue with the party-goers, and that they should welcome Science into their midst. The nine
Muses of music and the arts should also be invited. Seeing the central issue of ethics as eudemonia, the good life, Appiah believes that such a plenary gathering will best enable both its study and its achievement.

Nick Bostrom is director of the Future of Humanity Institute, Faculty of Philosophy and the James Martin 21st Century School, University of Oxford, Oxford OX14JJ, UK.

\title{
Music grown from garden weeds
}

\section{Umbel Ballits: Dylan Martorell \\ Craft Victoria, Melbourne \\ Until 28 June}

Botany, traditionally the preserve of watercolourists with a meticulous eye for detail, continues to inspire contemporary artists. Graphic designer and musician Dylan Martorell uses plant morphology as a starting point to create sound sculptures. His latest work is now on show in Melbourne, Australia.

Martorell begins by drawing plant-growth algorithms in pencil or ink on paper. Based on patterns he discerns in botanical structures, he uses a visual notation that enables the diagrams to function as musical scores. For this exhibition, he sourced plant structures from an Australian botanical manual by David Whibley and Trevor Christensen called Garden Weeds - Identification and Control (Botanic Gardens of Adelaide, 1991).

Moving beyond his precise drawings, Martorell also constructs less ordered three-dimensional sculptures. Evoking the original botanical structures, he incorporates found objects, musical instruments and living plants. He also digitally converts data from his drawings into music that slides from one frequency to another. Selections of the resulting 3.5minute sound tracks are played simultaneously in Craft Victoria's gallery, generating complex, overlapping sound patterns that create a fourth, aural dimension to his multimedia interpretation of the plant world. A small ensemble of musicians, including Martorell, occasionally rehearses and performs live music in the gallery, using the sculptures as instruments to generate sound.

"Currently I am creating hand-written scores based on the floral structures in various flowering plants such as racemes [unbranched flowers] and umbels [umbrella-like flowers]," says Martorell. Although the title of his exhibition - Umbel Ballits - mimics linnaean binomial classification, that was not his main intention. "Ballits is old Afro-American vernacular for ballads," he explains. "The sound pieces in my exhibition are based on pentatonic tunings, which were influenced by a variety of musical traditions, including the development of blues music in its journey from Africa to America."

The artist's musical scores take two forms. In one, he uses an upright trunk or stem to represent the base note or drone of the music, with branches or clusters providing extra musical notation. Scales and frequencies are represented on the horizontal axis and time is represented vertically. His second score pattern is shaped like a flower, with each petal representing a different base note, either played in clockwise succession or simultaneously. Using structures derived from local flora as his building blocks, Martorell draws, sculpts and composes multilayered and locationspecific artworks that challenge our perception of botanical art. Colin Martin is a writer based in London. 